\title{
Trends in Total Binge Drinks per Adult Who Reported Binge Drinking - United States, 2011-2017
}

\author{
Dafna Kanny, $\mathrm{PhD}^{1}$; Timothy S. Naimi, $\mathrm{MD}^{2}$; Yong Liu, $\mathrm{MD}^{1}$; Robert D. Brewer, $\mathrm{MD}^{1}$
}

Each year, excessive drinking accounts for one in 10 deaths among U.S. adults aged 20-64 years (1), and approximately $90 \%$ of adults who report excessive drinking* binge drink (i.e., consume five or more drinks for men or four or more drinks for women on a single occasion) (2). In 2015, 17.1\% of U.S. adults aged $\geq 18$ years reported binge drinking approximately once a week and consumed an average of seven drinks per binge drinking episode, resulting in $\mathbf{1 7 . 5}$ billion total binge drinks, or 467 total binge drinks per adult who reported binge drinking (3). CDC analyzed 2011-2017 Behavioral Risk Factor Surveillance System (BRFSS) data to assess trends in total annual binge drinks per adult who reported binge drinking in the United States overall and in the individual states. The age-adjusted ${ }^{\dagger}$ total annual number of binge drinks per adult who reported binge drinking increased significantly from 472 in 2011 to 529 in 2017. Total annual binge drinks per adult who reported binge drinking also increased significantly from 2011 to 2017 among those aged 35-44 years (26.7\%, from 468 to 593$)$ and $45-64$ years (23.1\%, from 428 to 527$)$. The largest percentage increases in total binge drinks per adult who reported binge drinking during this period were observed among those without a high school diploma (45.8\%) and those with household incomes $<\$ 25,000$ (23.9\%). Strategies recommended by the Community Preventive Services Task Force ${ }^{\$}$ for reducing excessive drinking (e.g., regulating alcohol outlet density) might reduce binge drinking and related health risks.

BRFSS is a state-based, random-digit-dialed landline and cellular telephone survey of noninstitutionalized, civilian U.S. adults aged $\geq 18$ years that collects data during each calendar month, yielding a representative sample for the year.9 Because important disparities in binge drinking behavior are not apparent based on an assessment of binge drinking prevalence alone, a new measure of binge drinking among U.S. adults was used (3). For each adult who reported binge drinking, the annual number of binge drinking episodes was calculated by multiplying the past 30-day frequency of binge

\footnotetext{
* Excessive alcohol consumption includes binge drinking (i.e., five or more drinks on an occasion for men and four or more drinks on an occasion for women), heavy weekly alcohol consumption (i.e., 15 or more drinks per week for men; eight or more drinks per week for women), and any drinking by pregnant women or those aged $<21$ years. https://www.cdc.gov/alcohol/fact-sheets/ alcohol-use.htm.

${ }^{\dagger}$ https://www.cdc.gov/nchs/data/statnt/statnt20.pdf.

${ }^{\S}$ https://www.thecommunityguide.org/topic/excessive-alcohol-consumption.

' https://www.cdc.gov/brfss/annual_data/2017/pdf/overview-2017-508.pdf.
}

drinking by 12 . The largest number of drinks consumed by adults who reported binge drinking during any occasion in the past 30 days was used to assess binge drinking intensity. The total annual number of binge drinks was calculated as the product of the annual number of binge drinking episodes and the binge drinking intensity among adults who reported binge drinking. Total annual binge drinks per adult who reported binge drinking was then determined by dividing total binge drinks by the weighted population estimates of U.S. adults who reported binge drinking.

To assess trends in total binge drinks per adult who reported binge drinking overall, by sociodemographic characteristics, and by state, CDC analyzed 2011-2017 BRFSS data. Total BRFSS sample sizes ranged from 441,456 (2015) to 506,467 (2011). The median survey response rates declined from $49.7 \%$ in 2011 to $45.9 \%$ in 2017 .** Data were weighted to each state's adult population and to each respondent's probability of selection. SAS (version 9.4; SAS Institute) and SAS-callable SUDAAN (version 10.0.3; RTI International) were used to calculate the mean of total binge drinks per adult who reported binge drinking, age-adjusted to the 2000 projected U.S. population. Linear and quadratic trends of the total annual binge drinks per adult who reported binge drinking were assessed by orthogonal polynomial contrast; only linear trends were consistent with the temporal distribution of the study data and were reported. Two-tailed t-tests were used to assess the statistical significance $(\mathrm{p}<0.05)$ of linear trends overall and among specific subgroups.

The age-adjusted prevalence of binge drinking decreased from $18.9 \%$ in 2011 to $18.0 \%$ in 2017 (Table 1). However, the overall age-adjusted total annual number of binge drinks per adult who reported binge drinking increased significantly (12.1\%) from 472 in 2011 to 529 in 2017 (Figure). The total number of binge drinks per adult who reported binge drinking also significantly increased from 2011 to 2017 , both for men (from 587 to 666) and women (from 256 to 290) (Table 1). During this period, the total number of binge drinks per adult who reported binge drinking also increased significantly: from

\footnotetext{
** Response rates for BRFSS are calculated using standards set by the American Association for Public Opinion Research response rate formula 4 (https:// www.aapor.org/AAPOR_Main/media/publications/StandardDefinitions20169theditionfinal.pdf). The response rate is the number of respondents who completed the survey as a proportion of all eligible and likely eligible persons.
} 
TABLE 1. Age-adjusted* binge drinking prevalence, ${ }^{\dagger}$ frequency, ${ }^{\S}$ intensity, ${ }^{\natural}$ and total binge drinks per adult who reported binge drinking** among adults aged $\geq 18$ years, ${ }^{\dagger \dagger}$ by selected characteristics and year - Behavioral Risk Factor Surveillance System, United States, ${ }^{\S \S}$ 2011-2017

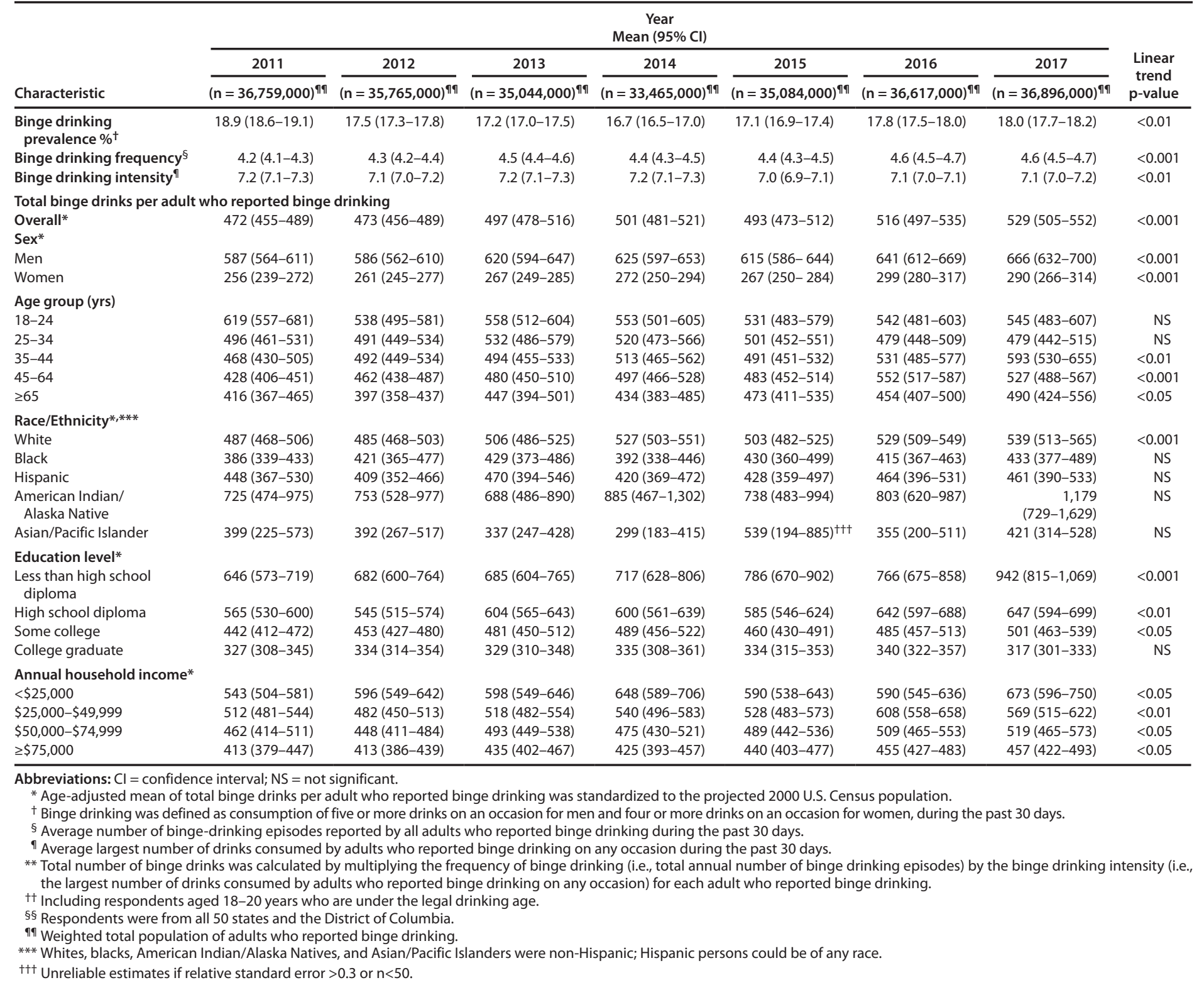

468 to 593 among those aged 35-44 years, from 428 to 527 among those aged 45-64 years, from 416 to 490 among those aged $\geq 65$ years, and from 487 to 539 among non-Hispanic white adults. In addition, the total number of binge drinks per adult who reported binge drinking increased significantly among persons with some college education or less and across all income categories. However, from 2011 to 2017, the largest percentage increases in total number of binge drinks per adult who reported binge drinking were among those with less than a high school diploma (45.8\%; from 646 to 942) and those with household incomes $<\$ 25,000$ (23.9\%; from 543 to 673$)$.
In 2017, the total number of binge drinks per adult who reported binge drinking ranged from 320 in Massachusetts to 1,219 in Wyoming (Table 2). From 2011 to 2017, total number of binge drinks per adult who reported binge drinking increased significantly in nine states (Idaho, Indiana, Maine, Montana, New Jersey, New York, North Dakota, Ohio, and Virginia), decreased significantly in Massachusetts and West Virginia, and did not change significantly in the other 39 states and the District of Columbia. 
FIGURE. Age-adjusted* annual number of binge drinks per adult who reported binge drinking ${ }^{\dagger}$ among adults aged $\geq 18$ years, ${ }^{\S}$ by sex Behavioral Risk Factor Surveillance System, United States, "2011-2017

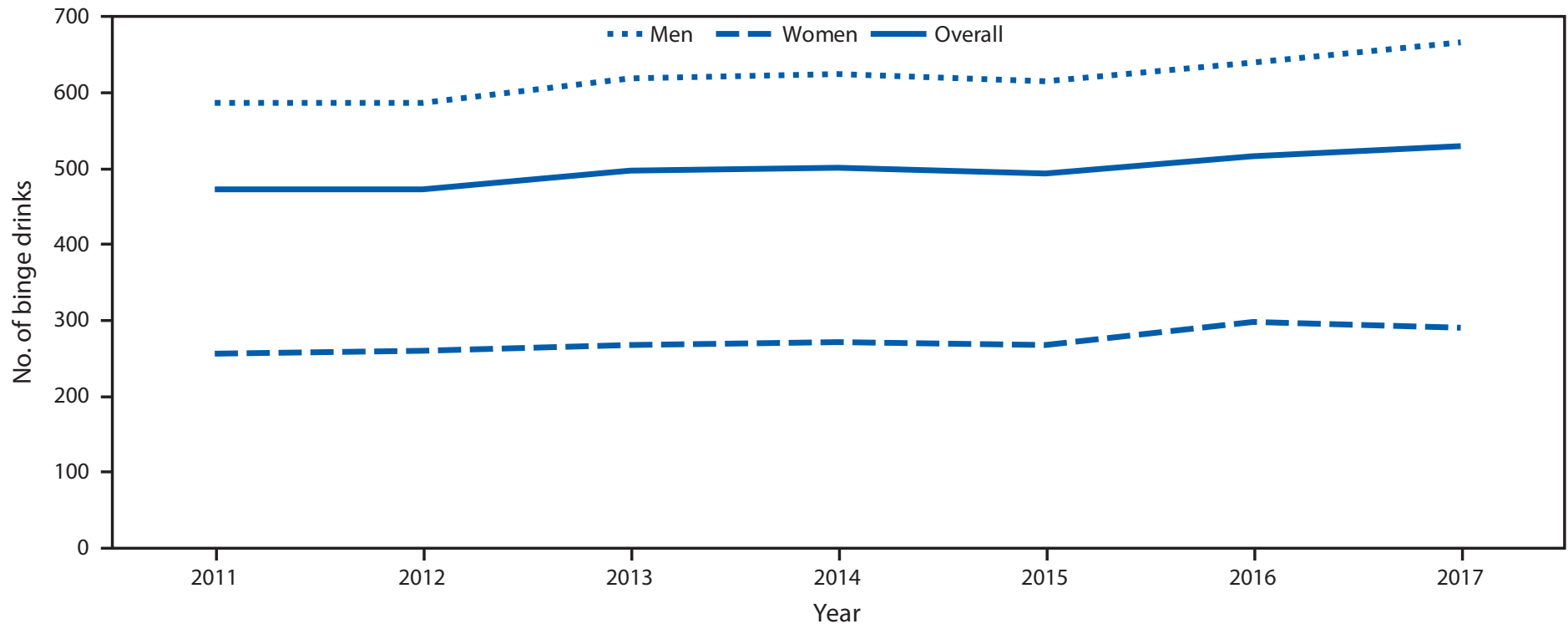

* Age-adjusted mean of total binge drinks per adult who reported binge drinking was standardized to the projected 2000 U.S. Census population.

† Total number of binge drinks was calculated by multiplying the frequency of binge drinking (i.e., total annual number of binge drinking episodes) by the binge drinking intensity (i.e., the largest number of drinks consumed by adults who reported binge drinking on any occasion) for each adult who reported binge drinking.

$\S$ Including respondents aged $18-20$ years who were under the legal drinking age.

I Respondents were from all 50 states and the District of Columbia.

\section{Discussion}

The total annual number of binge drinks consumed per U.S. adult who reported binge drinking increased significantly by $12 \%$ from 2011 to 2017 , including among non-Hispanic white adults and those aged $\geq 35$ years. These increases are consistent with other recent evidence of an approximately $30 \%$ increase in high-risk drinking, ${ }^{\dagger \dagger}$ including binge-level alcohol consumption, particularly among middle-aged and older adults (4). Because binge drinking contributes a substantial proportion of all alcohol consumption in the United States, these increases also are consistent with an increase in per capita alcohol consumption (derived from sales and shipment data) in the United States, ${ }^{\$ \$}$ from 2.29 gallons in 2011 to 2.34 gallons in 2017 .

The finding that the total number of binge drinks consumed per U.S. adult who reported binge drinking increased significantly among those with lower education and income levels is also consistent with a recent study that found the majority of persons reporting prescription opioid misuse also are adults who reported binge drinking, and that prescription opioid misuse tends to be most common among persons with lower household incomes (5). Socioeconomic disparities in the total

\footnotetext{
$\dagger^{\dagger}$ High-risk drinking was defined as drinking four or more standard drinks on any day for women or five or more standard drinks on any day (not necessarily during one sitting) for men.

$\$ \$$ https://pubs.niaaa.nih.gov/publications/surveillance113/CONS17.htm.
}

\section{Summary}

What is already known about this topic?

In 2015, 37 million (17.1\%) U.S. adults reported binge drinking approximately once a week and consumed an average of seven drinks per binge drinking episode, resulting in approximately 450 total binge drinks per adult who reported binge drinking annually.

What is added by this report?

From 2011 to 2017, the total number of binge drinks consumed annually by U.S. adults who reported binge drinking increased significantly, from 472 to 529 . Significant increases were observed among adults who reported binge drinking of both sexes, those aged $\geq 35$ years, and those with lower educational levels and household incomes.

What are the implications for public health practice?

Application of population-level evidence-based prevention strategies (e.g., regulating alcohol outlet density) could reduce binge drinking and related harms.

number of binge drinks per adult who reported binge drinking also might have contributed to the lower life expectancies reported among persons with lower socioeconomic status in the United States (G).

The total annual number of binge drinks per adult who reported binge drinking did not change significantly in most states from 2011 to 2017, although it did increase significantly in nine states. At the state or local levels, examining the total 
TABLE 2. Age-adjusted* total number of binge drinks per adult who reported binge drinking ${ }^{\dagger}$ among adults aged $\geq 18$ years, $\$$ by state Behavioral Risk Factor Surveillance System, United States, 2011-2017

\begin{tabular}{|c|c|c|c|c|c|c|c|c|}
\hline \multirow[b]{2}{*}{ State } & \multicolumn{7}{|c|}{$\begin{array}{c}\text { Year } \\
\text { Mean }(95 \% \mathrm{Cl})\end{array}$} & \multirow{2}{*}{$\begin{array}{l}\text { Linear } \\
\text { trend } \\
\text { p-value }\end{array}$} \\
\hline & 2011 & 2012 & 2013 & 2014 & 2015 & 2016 & 2017 & \\
\hline Alabama & $520(257-783)$ & $530(423-637)$ & $414(320-507)$ & $457(375-539)$ & $570(450-690)$ & $481(400-562)$ & $451(296-606)$ & NS \\
\hline Alaska & $535(341-729)$ & $466(369-562)$ & $640(415-865)$ & $702(529-875)$ & $649(447-852)$ & $405(326-484)$ & $683(376-989)$ & NS \\
\hline Arizona & 412 (335-489) & $405(333-476)$ & 729 (486-972) & 499 (409-589) & $547(403-690)$ & $522(431-613)$ & $492(419-566)$ & NS \\
\hline Arkansas & $710(332-1,088)$ & 732 (479-985) & $748(334-1,161)$ & $449(357-541)$ & $819(552-1,086)$ & $843(479-1,207)$ & $774(512-1,036)$ & NS \\
\hline California & $417(359-476)$ & $372(323-420)$ & $445(370-520)$ & $470(391-549)$ & $400(342-459)$ & $430(358-502)$ & $470(379-562)$ & NS \\
\hline Colorado & $390(334-445)$ & $409(353-464)$ & $450(385-516)$ & $403(352-453)$ & $426(367-486)$ & $430(358-502)$ & $434(368-500)$ & NS \\
\hline Connecticut & $410(306-514)$ & $483(357-608)$ & $455(333-578)$ & $402(324-480)$ & $565(412-719)$ & 489 (329-648) & $365(287-442)$ & NS \\
\hline Delaware & $543(378-709)$ & $459(372-545)$ & $432(339-525)$ & $482(351-614)$ & $435(319-551)$ & $560(391-729)$ & 640 (301-979) & NS \\
\hline $\begin{array}{l}\text { District of } \\
\text { Columbia }\end{array}$ & $353(281-425)$ & $325(264-387)$ & 354 (289-419) & $379(273-484)$ & $323(252-394)$ & $342(265-418)$ & $334(267-401)$ & NS \\
\hline Florida & $497(421-573)$ & $513(422-603)$ & $559(485-632)$ & $511(426-596)$ & $455(378-531)$ & $617(453-781)$ & 619 (489-749) & NS \\
\hline Georgia & $487(394-579)$ & $548(411-685)$ & $529(404-654)$ & $535(425-646)$ & $496(377-616)$ & $576(424-727)$ & $473(367-580)$ & NS \\
\hline Hawaii & $636(476-796)$ & $703(594-812)$ & $634(514-755)$ & $577(493-661)$ & $635(529-741)$ & $646(512-781)$ & $622(520-724)$ & NS \\
\hline Idaho & $433(329-538)$ & $434(360-509)$ & $556(429-682)$ & $448(339-558)$ & $533(402-663)$ & $520(404-636)$ & $793(506-1,079)$ & $<0.05$ \\
\hline Illinois & $497(424-571)$ & $499(396-602)$ & $525(426-623)$ & $517(415-620)$ & $451(370-532)$ & $532(428-637)$ & 441 (363-519) & NS \\
\hline Indiana & $482(397-566)$ & $511(430-592)$ & $562(455-669)$ & $582(453-711)$ & $521(412-631)$ & $625(517-733)$ & $699(588-810)$ & $<0.01$ \\
\hline lowa & $580(481-679)$ & $466(398-535)$ & $568(471-664)$ & $560(433-688)$ & $523(435-611)$ & $553(468-639)$ & $586(499-672)$ & NS \\
\hline Kansas & $480(420-539)$ & $532(444-619)$ & $516(463-569)$ & $495(422-568)$ & $475(423-526)$ & $570(470-669)$ & $505(429-582)$ & NS \\
\hline Kentucky & $641(527-756)$ & $797(630-964)$ & $575(471-679)$ & 763 (577-950) & $722(585-858)$ & $833(593-1,072)$ & $699(554-843)$ & NS \\
\hline Louisiana & $522(422-623)$ & $581(431-730)$ & $635(413-858)$ & $522(343-702)$ & $609(475-742)$ & 416 (329-504) & 505 (402-609) & NS \\
\hline Maine & $518(437-600)$ & $489(416-562)$ & $508(418-597)$ & $567(450-684)$ & $510(435-586)$ & $595(487-703)$ & $762(503-1,021)$ & $<0.05$ \\
\hline Maryland & $450(324-576)$ & $391(336-446)$ & $468(374-561)$ & $374(310-437)$ & $477(365-589)$ & $442(382-501)$ & $477(384-571)$ & NS \\
\hline Massachusetts & $416(369-463)$ & $499(420-578)$ & $448(377-518)$ & $471(387-555)$ & $440(333-547)$ & $386(319-452)$ & $320(267-372)$ & $<0.01$ \\
\hline Michigan & $567(473-661)$ & $478(399-556)$ & $468(413-523)$ & $602(494-711)$ & $609(491-727)$ & $582(475-690)$ & $531(454-608)$ & NS \\
\hline Minnesota & $400(352-447)$ & $421(366-475)$ & $445(385-504)$ & $410(352-467)$ & $452(408-496)$ & $427(378-475)$ & $409(365-453)$ & NS \\
\hline Mississippi & $665(502-827)$ & $512(412-612)$ & $631(496-766)$ & $521(372-669)$ & $761(425-1,097)$ & $622(449-794)$ & $640(437-842)$ & NS \\
\hline Missouri & $535(433-636)$ & $479(371-588)$ & $614(438-791)$ & $592(456-728)$ & 653 (488-819) & 603 (499-708) & $493(408-578)$ & NS \\
\hline Montana & $467(403-530)$ & $481(418-544)$ & $454(394-514)$ & $550(435-665)$ & $498(398-598)$ & $475(377-572)$ & $658(503-813)$ & $<0.05$ \\
\hline Nebraska & $460(419-502)$ & $526(463-589)$ & $500(426-574)$ & $472(417-528)$ & $472(385-559)$ & $479(413-545)$ & $477(414-540)$ & NS \\
\hline Nevada & $480(377-582)$ & $470(389-551)$ & 677 (487-868) & $448(333-564)$ & $623(377-868)$ & $421(304-538)$ & $483(341-624)$ & NS \\
\hline New Hampshire & $530(348-712)$ & $586(408-764)$ & $399(328-470)$ & $458(355-560)$ & $414(331-497)$ & $479(388-571)$ & $506(366-647)$ & NS \\
\hline New Jersey & $438(330-546)$ & $344(287-402)$ & $355(311-399)$ & $394(335-452)$ & $429(234-624)$ & $473(352-595)$ & $563(436-690)$ & $<0.05$ \\
\hline New Mexico & $442(376-508)$ & $512(427-597)$ & $480(407-552)$ & $580(478-682)$ & $440(351-528)$ & $512(369-654)$ & $558(428-688)$ & NS \\
\hline New York & $364(293-435)$ & $370(303-438)$ & $368(316-420)$ & $375(281-469)$ & $389(344-435)$ & $448(401-495)$ & $481(400-561)$ & $<0.01$ \\
\hline North Carolina & $483(384-582)$ & $463(397-529)$ & $465(374-556)$ & $464(351-577)$ & $434(356-511)$ & $523(376-671)$ & $445(253-636)$ & NS \\
\hline North Dakota & $436(336-535)$ & $471(389-553)$ & $459(396-523)$ & $624(462-785)$ & 547 (444-649) & $610(506-713)$ & $505(434-576)$ & $<0.05$ \\
\hline Ohio & $474(402-546)$ & $541(466-616)$ & $488(428-548)$ & $606(481-731)$ & $608(444-772)$ & $633(527-738)$ & $764(603-925)$ & $<0.01$ \\
\hline Oklahoma & $604(459-748)$ & $583(490-675)$ & $616(465-767)$ & $539(438-641)$ & $555(417-693)$ & $563(373-753)$ & $490(389-592)$ & NS \\
\hline Oregon & $455(361-549)$ & $457(358-557)$ & $508(400-615)$ & $406(335-477)$ & $400(322-479)$ & $383(325-442)$ & $425(356-494)$ & NS \\
\hline Pennsylvania & $472(406-537)$ & $497(412-582)$ & $599(492-707)$ & $450(376-525)$ & $471(351-590)$ & $505(422-589)$ & $584(454-715)$ & NS \\
\hline Rhode Island & 370 (290-449) & $427(346-508)$ & 416 (338-494) & $407(325-490)$ & $562(271-853)$ & $435(331-538)$ & $533(378-688)$ & NS \\
\hline South Carolina & $537(431-643)$ & $595(455-735)$ & $512(423-602)$ & $519(436-602)$ & $625(529-721)$ & $478(408-548)$ & $510(437-584)$ & NS \\
\hline South Dakota & $423(338-507)$ & $497(396-597)$ & $458(365-551)$ & $456(311-602)$ & $425(344-505)$ & $491(357-625)$ & $590(439-742)$ & NS \\
\hline Tennessee & $421(214-628)$ & $428(321-536)$ & $319(196-443)$ & $505(335-676)$ & $529(395-664)$ & $534(423-646)$ & $497(367-626)$ & NS \\
\hline Texas & $525(431-620)$ & $512(430-594)$ & $536(448-623)$ & $545(450-640)$ & $516(425-608)$ & $546(462-630)$ & $568(458-679)$ & NS \\
\hline Utah & 554 (459-649) & $471(394-549)$ & $576(457-694)$ & $667(530-803)$ & $457(389-525)$ & $630(503-757)$ & $549(442-656)$ & NS \\
\hline Vermont & $473(395-551)$ & $454(357-551)$ & $472(372-572)$ & $627(335-919)$ & $488(381-595)$ & $685(540-831)$ & $490(395-585)$ & NS \\
\hline Virginia & $409(343-476)$ & $441(364-517)$ & $440(367-513)$ & $538(431-645)$ & $523(409-637)$ & $562(450-674)$ & $531(439-624)$ & $<0.01$ \\
\hline Washington & $374(319-429)$ & $482(349-615)$ & $444(382-506)$ & $441(362-519)$ & $384(321-447)$ & $427(363-491)$ & $428(376-480)$ & NS \\
\hline West Virginia & $792(575-1,009)$ & 761 (573-949) & 799 (639-959) & $886(602-1,171)$ & $517(419-614)$ & 766 (574-959) & 565 (450-679) & $<0.05$ \\
\hline Wisconsin & $511(392-631)$ & $514(421-607)$ & $452(393-511)$ & $490(385-594)$ & $493(414-572)$ & $460(390-529)$ & $478(378-578)$ & NS \\
\hline Wyoming & $617(448-787)$ & $547(371-723)$ & $686(488-884)$ & $541(357-725)$ & $431(336-526)$ & $513(355-672)$ & $1,219(586-1,852)$ & NS \\
\hline
\end{tabular}

Abbreviations: $\mathrm{Cl}=$ confidence interval; $\mathrm{NS}=$ not significant.

* Age-adjusted mean of total binge drinks per adult who reported binge drinking was standardized to the projected 2000 U.S. Census population.

† Total number of binge drinks was calculated by multiplying the frequency of binge drinking (i.e., total annual number of binge drinking episodes) by the binge drinking intensity (i.e., the largest number of drinks consumed by adults who reported binge drinking on any occasion) for each adult who reported binge drinking.

$\S$ Including respondents aged $18-20$ years who are under the legal drinking age. 
number of binge drinks consumed by adults who reported binge drinking is a relatively new way to assess binge drinking and related harms. However, by combining public health surveillance data on the prevalence, frequency, and intensity of binge drinking, this measure provides a more complete and sensitive indicator of this health risk and facilitates assessment of sociodemographic and geographic disparities in binge drinking. This measure also might be useful for assessing health risks related to binge drinking (e.g., opioid misuse) (5), and for planning and evaluating effective strategies for preventing binge drinking at the state and local levels.

The findings in this report are subject to at least four limitations. First, BRFSS data are self-reported, and the BRFSS substantially underestimates alcohol consumption in the United States relative to alcohol sales data (7). Second, the BRFSS measure of the largest number of drinks among adults who reported binge drinking might have resulted in higher estimates of binge drinking intensity than would other survey methods, such as when collecting information on the most recent binge drinking episode for adults who reported binge drinking, including the number of drinks consumed by beverage type (8). However, because the underreporting of alcohol consumption tends to be greater among binge drinkers than among non-binge drinkers and tends to increase with binge drinking intensity (9), the prevalence, frequency, and intensity of binge drinking are likely to have been substantially underestimated in this study. Third, similar to other telephone surveys, BRFSS response rates have been declining, which could affect the representativeness of the survey responses. However, BRFSS response rates did not change substantially during the study period, and were, therefore, unlikely to have affected trends. Finally, BRFSS does not survey institutionalized adults, which limits the generalizability of the findings to noninstitutionalized persons.

Reducing binge drinking is essential to reducing excessive drinking at the population level. These findings highlight the need to reduce the total number of binge drinks per adult who reported binge drinking by reducing the prevalence, frequency, and intensity of binge drinking. Moreover, monitoring binge drinking prevalence alone, the most commonly used measure of binge drinking, portrays an incomplete picture of the problem of binge drinking, and might mask important sociodemographic and socioeconomic disparities in binge drinking behavior. Binge drinking is also strongly affected by the social context within which persons make their drinking decisions. For example, persons living in states with more restrictive alcohol policies are also less likely to binge drink and experience alcohol-attributable harms, including motor vehicle crash deaths, alcoholic liver cirrhosis, and alcohol-involved homicides and suicides than are persons living in states with less restrictive alcohol policies (10). Evidence-based prevention strategies to decrease excessive drinking that the Community Preventive Services Task Force recommends include increasing alcohol taxes, regulating the number and concentration of alcohol outlets in communities, and enforcing minimum legal drinking age laws.

Corresponding author: Dafna Kanny, dkanny@cdc.gov, 770-488-5411.

${ }^{1}$ Division of Population Health, National Center for Chronic Disease Prevention and Health Promotion, CDC; ${ }^{2}$ Section of General Internal Medicine, Boston Medical Center, Massachusetts.

All authors have completed and submitted the International Committee of Medical Journal Editors form for disclosure of potential conflicts of interest. No potential conflicts of interest were disclosed.

\section{References}

1. Stahre M, Roeber J, Kanny D, Brewer RD, Zhang X. Contribution of excessive alcohol consumption to deaths and years of potential life lost in the United States. Prev Chronic Dis 2014;11:130293. https://doi. org/10.5888/pcd11.130293

2. Esser MB, Hedden SL, Kanny D, Brewer RD, Gfroerer JC, Naimi TS. Prevalence of alcohol dependence among US adult drinkers, 2009-2011. Prev Chronic Dis 2014;11:E206. https://doi.org/10.5888/pcd11.140329

3. Kanny D, Naimi TS, Liu Y, Lu H, Brewer RD. Annual total binge drinks consumed by U.S. adults, 2015. Am J Prev Med 2018;54:486-96. https://doi.org/10.1016/j.amepre.2017.12.021

4. Grant BF, Chou SP, Saha TD, et al. Prevalence of 12-month alcohol use, high-risk drinking, and DSM-IV alcohol use disorder in the United States, 2001-2002 to 2012-2013: results from the National Epidemiologic Survey on Alcohol and Related Conditions. JAMA Psychiatry 2017;74:911-23. https://doi.org/10.1001/jamapsychiatry.2017.2161

5. Esser MB, Guy GP Jr, Zhang K, Brewer RD. Binge drinking and prescription opioid misuse in the United States, 2012-2014. Am J Prev Med 2019;57:197-208. https://doi.org/10.1016/j.amepre.2019.02.025

6. Chetty R, Stepner M, Abraham S, et al. The association between income and life expectancy in the United States, 2001-2014. JAMA 2016;315:1750-66. https://doi.org/10.1001/jama.2016.4226

7. Nelson DE, Naimi TS, Brewer RD, Roeber J. US state alcohol sales compared to survey data, 1993-2006. Addiction 2010;105:1589-96. https://doi.org/10.1111/j.1360-0443.2010.03007.x

8. Esser MB, Kanny D, Brewer RD, Naimi TS. Binge drinking intensity: a comparison of two measures. Am J Prev Med 2012;42:625-9. https:// doi.org/10.1016/j.amepre.2012.03.001

9. Northcote J, Livingston M. Accuracy of self-reported drinking: observational verification of 'last occasion' drink estimates of young adults. Alcohol Alcohol 2011;46:709-13. https://doi.org/10.1093/ alcalc/agr138

10. Xuan Z, Blanchette J, Nelson TF, Heeren T, Oussayef N, Naimi TS. The alcohol policy environment and policy subgroups as predictors of binge drinking measures among US adults. Am J Public Health 2015;105:816-22. https://doi.org/10.2105/AJPH.2014.302112 